May 2019

\title{
Evaluation of cervical spine posture after functional therapy with twin-block appliances: A retrospective cohort study
}

Adeel Tahir Kamal

Aga Khan University, adeel.tahir@aku.edu

Mubassar Fida

Aga Khan University, mubassar.fida@aku.edu

Follow this and additional works at: https://ecommons.aku.edu/

pakistan_fhs_mc_surg_dent_oral_maxillofac

\section{Recommended Citation}

Kamal, A., Fida, M. (2019). Evaluation of cervical spine posture after functional therapy with twin-block appliances: A retrospective cohort study. American Board of Orthodontics, 155(5), 656-661.

Available at: https://ecommons.aku.edu/pakistan_fhs_mc_surg_dent_oral_maxillofac/108 


\title{
Evaluation of cervical spine posture after functional therapy with twin-block appliances: A retrospective cohort study
}

\author{
Adeel Tahir Kamal and Mubassar Fida \\ Karachi, Pakistan
}

\begin{abstract}
Introduction: It has been postulated that a change in cervical posture occurs as a consequence of forward repositioning of the mandible. Therefore, the objective of this study was to compare the cervical spine posture between subjects with and without functional appliance therapy. Methods: A retrospective cohort study was conducted with the use of pre- and post-functional therapy cephalograms of orthodontic patients. A total of 60 subjects was composed of 2 groups of 30 subjects each: those who underwent treatment with a twinblock (TB) functional appliance and a control group selected from the Bolton-Brush Growth Study. Three sagittal and 7 cervical vertebral parameters were compared between the groups. The Wilcoxon signed-rank test was used to compare pre- and postfunctional mean angular measurements. The Mann-Whitney $U$ test was used to compare the mean changes in cervical parameters between the groups. Results: A significant difference existed between pre- and postfunctional SNB $(P<0.001)$ and ANB $(P<0.001)$ angles, showing a change in maxillomandibular relationship. Comparison of mean changes in angular measurements between the 2 groups showed a significant difference $(P=0.032)$ in the sella-nasion to odontoid process tangent (SNOPT) angle. The SN-OPT angle predicted that the probability of developing an altered cervical posture with the TB appliance is 2.08 times greater than without the TB appliance. Conclusions: SN-OPT angle can predict a change in skeletal relationships after treatment with the TB functional appliance. The TB causes the craniocervical posture to be more upright. Subjects with reduced vertical dimensions have greater change in cervical posture. (Am J Orthod Dentofacial Orthop 2019;155:656-61)
\end{abstract}

$\mathrm{F}$ unctional appliance treatment is considered to be a valuable strategy to overcome deficient growth of the mandible. In a study by Aslam et al, ${ }^{1}$ Class 11 Division 1 malocclusion had a prevalence of $41 \%$ in patients who presented for orthodontic treatment. Many of these patients are growing, and numerous functional appliances can be prescribed for the correction of skeletal relationships. Functional appliances alter the activity of various muscle groups that influence the function and position of the mandible. This generates pressure from the stretch of muscles and surrounding soft tissues, which is also known as "viscoelastic stretch." ${ }^{2}$ The redirection of forces produced by the appliance is

Section of Dentistry, Department of Surgery, Aga Khan University Hospital, Karachi, Pakistan.

All authors have completed and submitted the 1CMJE Form for Disclosure of Potential Conflicts of Interest, and none were reported.

Address correspondence to: Mubassar Fida, Section of Dentistry, Department of Surgery, Aga Khan University Hospital, PO Box 3500, Stadium Road, Karachi 74800, Pakistan; e-mail, mubassar.fida@aku.edu.

Submitted, July 2017; revised and accepted, June 2018.

$0889-5406 / \$ 36.00$

(C) 2019 by the American Association of Orthodontists. All rights reserved.

https://doi.org/10.1016/j.ajodo.2018.06.012 transmitted to the underlying skeletal tissues and brings about orthodontic and orthopedic changes. ${ }^{3}$

The twin block (TB) was introduced by $\mathrm{Clark}^{4}$ in 1982. Since then, it has become the most preferred functional appliance. ${ }^{5}$ This removable appliance owes its increasing popularity to its uncomplicated design and ease of use..$^{5}$ It consists of separate upper and lower acrylic units which position the mandible forward through interlocking occlusal bite blocks. ${ }^{3,5}$ The 2piece design (Fig 1) facilitates speech and mastication and has proved to be associated with good patient compliance. ${ }^{2,4}$ Extensive research on the skeletal and dental effects of the $\mathrm{TB}^{6,7}$ has shown varied results. ${ }^{8,9}$ The reason for these inconsistencies could be the difficulty in beginning treatment at the maximum growth spurt and using unreliable reference lines during cephalometric analysis. ${ }^{10,11}$

The association between the maxillomandibular relationships, the cervical column, and head posture has been investigated in the past. ${ }^{71}$ As early as 1926, Schwarz ${ }^{13}$ observed an association between the head posture and the jaw position. The head posture is claimed to be affected by the mode of breathing and 


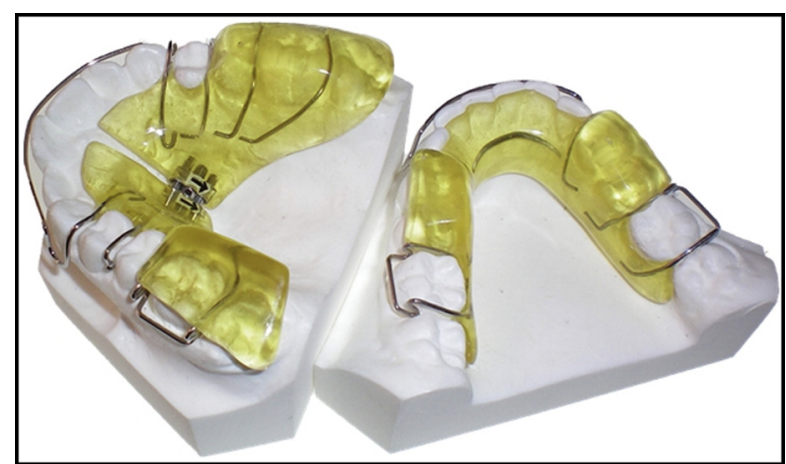

Fig 1. Twin-block appliance.

consequently to have effects on the craniofacial growth. ${ }^{14}$ Gresham and Smithells ${ }^{15}$ and Morris et al ${ }^{16}$ revealed radiographic evidence that children who habitually lack an upright head posture have an Angle Class 11 malocclusion, long-face syndrome, and kyphosis of the cervical spine. In addition, Sidlauskiene et $\mathrm{al}^{17}$ found that the dental overjet and overbite were significantly greater in patients with kyphotic posture.

Because the TB is one of the most common functional appliances prescribed to patients for dentofacial orthopedic purposes, it is necessary to evaluate its treatment effects. A survey of the pertinent literature showed many studies that have reported effects of the TB with the use of routine skeletal and dental landmarks, but none reporting the effects of the TB on cervical posture. ${ }^{18,19}$ The objective of the present study was to compare the cervical spine posture between subjects with and without TB therapy. The null hypothesis was that no differences are observed in the cervical spine posture between the 2 groups.

\section{MATERIAL AND METHODS}

A retrospective cohort was conducted with the use of pre- (PF1) and post- (PF2) functional therapy cephalograms of orthodontically treated patients. A comparison or unexposed group was selected as a control from the Bolton-Brush Growth Study. ${ }^{20}$ The sample size was calculated with the use of OpenEpi software. Tecco et $\mathrm{al}^{21}$ reported that the mean value for the sellanasion to the odontoid process tangent (SN-OPT) angle in patients treated with the Frankel 11 appliance was $87.5 \pm 3^{\circ}$ compared with $83.3 \pm 4.5^{\circ}$ in the control group. Keeping the power of the study as $90 \%$ and alpha as 0.05 , it was calculated that at least 28 subjects were required in each group. A total of 60 subjects were included in this study. Because sex is an effect modifier, equal numbers of male $(n=15)$ and female $(n=15)$ patients were included in each group. The mean age of
Table I. Pretreatment severity of Class 11 molar relationships between the groups

\begin{tabular}{lll} 
Severity & Control & Twin block \\
\hline Full cusp & 30 & 30 \\
Three-quarter cusp & - & - \\
Half cusp & - & - \\
Quarter cusp & - & -
\end{tabular}

subjects in the exposed group was $11.8 \pm 1.5$ years and in the unexposed group was $11.6 \pm 2.0$ years.

All subjects presenting at the orthodontic clinics of our university hospital with skeletal Class 11 malocclusion (ANB $>5^{\circ}$ ) due to mandibular retrognathism (SNB $<78^{\circ}$ ), with full cusp Class 11 molar, canine, and incisor relationships, and in their pubertal growth spurt (CS3) were included in this study. Those subjects who had extracted or missing teeth, craniofacial syndromes, history of trauma or surgery involving facial structures, or a systemic disease that affects the growth and development were excluded.

The control group was taken from the Bolton-Brush Growth Study and was matched with experimental subjects on the basis of skeletal age, sex, molar relationships (Table 1), and SNB and ANB angles. Cephalograms $\left(T_{1}\right)$ were matched between a subject serving as a control and a subject in the exposed group. Subsequently, a cephalogram $\left(T_{2}\right)$ of the same individual was evaluated after TB appliance therapy. Both groups showed a circumpubertal stage of skeletal growth (CS3) at $\mathrm{T}_{1}$ as reported by Baccetti et al. ${ }^{22}$ Each subject's chronologic age and cervical stage were recorded. The mean duration of TB treatment was $11.83 \pm 1.8$ months. All subjects were instructed to wear the appliance for a minimum of 20 hours/day except during eating, brushing, and contact sports. Compliance with the TB therapy was monitored by recording the wear time as reported by the patient and his or her parents on every visit, the wear of the appliance, the reduction of overjet of at least $1 \mathrm{~mm}$ between the most proclined incisor at monthly intervals and the observation of the pterygoid effect. If there wasn't a reduction in overjet and absence of these factors for 2 consecutive months, it indicated a failure to wear the appliance. TB appliance therapy was considered to be successful when a class 1 molar relationship was achieved and patients then underwent a PF2 cephalogram.

All cephalograms were taken with rigid head fixation and a $165 \mathrm{~cm}$ film to tube distance with the use of an Orthoralix R9200 (Gendex-Kavo, Milan, Itay). Cephalograms were traced manually with a $0.5-\mathrm{mm}$ lead pencil on acetate sheets on an illuminator. Angular readings were measured with the help of a protractor. 
The PF1 and PF2 cephalograms were evaluated for 3 sagittal, 1 vertical, and 7 cervical parameters. The sagittal parameters, SNA, SNB, and ANB, were measured to determine any change in the skeletal relationships in the anteroposterior dimension. The $\mathrm{SN}-\mathrm{GoGn}$ was measured to determine changes in the vertical dimension. The odontoid process tangent (OPT) was drawn through the most posteroinferior point on the second cervical vertebra (C2). The anterior and inferior angles created with sella-nasion (SN), palatal plane (PP), and mandibular plane (SN-GoGn) were measured to determine any change in the upper cervical posture. The cervical vertebral tangent (CVT) was drawn through the most posteroinferior point on the fourth cervical vertebra (C4). The anterior and inferior angles created with the aforementioned planes and the angle between OPT and CVT were used to determine any change in the middle cervical posture (Fig 2).

To test intraexaminer reliability, 30 radiographs were randomly selected, retraced, and remeasured by the principal investigator. The intraclass correlation coefficient showed a high degree of correlation between the 2 readings (Table 11 ).

Data were entered and analyzed in SPSS for Windows (version 20.0; SPSS, Chicago, 111). Descriptive statistics were used for the calculation of mean age. The Shapiro-Wilk test was applied to determine the normality of the data, which showed a nonnormal distribution. The Wilcoxon signed-rank test was used to compare PF1 and PF2 means in both the groups. The Mann-Whitney $U$ test was used to compare the mean changes between the 2 groups. The probability of altered cervical posture after TB therapy was also calculated.

\section{RESULTS}

The PF1 angular measurements did not show a significant difference between sexes, so results were not stratified accordingly.

The medians and interquartile ranges of PF1 and PF2 linear and angular sagittal and cervical angular measurements are presented in Table 111. The PF1 and PF2 sagittal values, ie, SNB and ANB, showed a significant difference $(P<0.001)$ in the exposed group. A significant difference existed between the $\mathrm{T} 1$ and $\mathrm{T} 2$ readings for the SN-OPT angle $(P=0.033)$ and MP-CVT angle $(P=0.013)$ in the unexposed group.

The change in the PF1 and PF2 values are presented in Table IV. A significant difference was found between SNB $(P<0.001)$, ANB $(P<0.001)$, and SN-OPT $(P=0.032)$.

The probabilities of developing an altered cervical posture with different angular measurements are presented in Table $\mathrm{V}$.

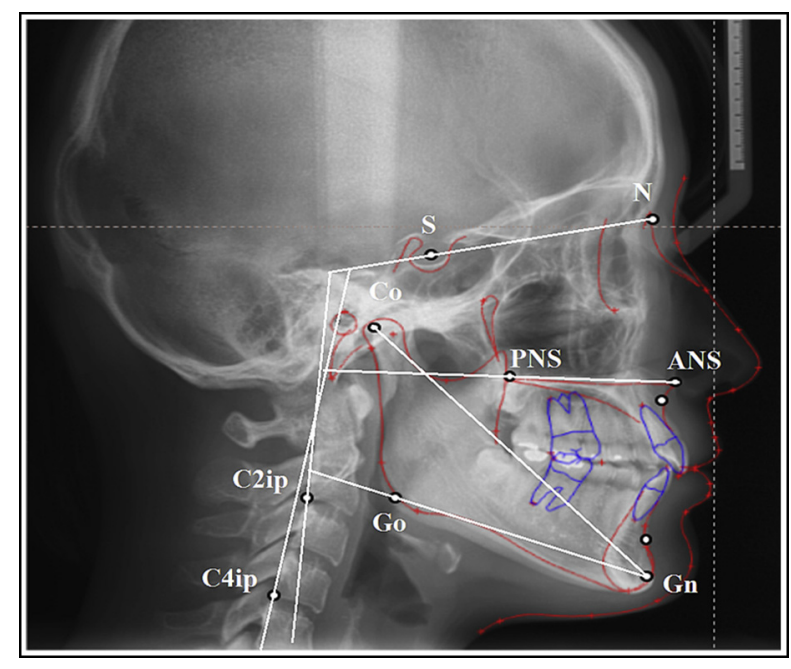

Fig 2. Cephalometric planes.

Table II. Intraexaminer reliability, median (interquartile range)

$\begin{array}{lccc}\text { Parameter } & \text { 1st reading }(n=30) & \text { 2nd reading }(n=30) & \text { ICC } \\ \text { SNA }^{\circ} & 82.0(79-83.2) & 81.0(78.7-82.2) & 0.979 \\ \text { SNB }^{\circ} & 75.0(72.7-77.0) & 75.0(72.0-77.0) & 0.965 \\ \text { ANB }^{\circ} & 6.0(5.0-8.0) & 6.0(5.0-8.0) & 0.873 \\ \text { SN-OPT }^{\circ} & 104.0(99.0-110.0) & 104.0(99.0-110.0) & 0.953 \\ \text { MP-OPT }^{\circ} & 73.5(70.0-80.2) & 72.5(69-80.5) & 0.788 \\ \text { PP-OPT }^{\circ} & 98.0(94.7-102.2) & 96.0(92.0-100.2) & 0.978 \\ \text { SNCVT }^{\circ} & 104.5(100.7-113.5) & 103.0(100.0-110.0) & 0.985 \\ \text { PP-CVT }^{\circ} & 100.0(95.0-106.2) & 99.5(95.7-105.2) & 0.962 \\ \text { MP-CVT }^{\circ} & 76.5(71.5-82.2) & 75.5(70.5-82.0) & 0.997 \\ \text { OPT-CVT }^{\circ} & 5.0(3.0-7.2) & 4.0(2.0-6.2) & 0.954\end{array}$

ICC, Intraclass correlation coefficient.

\section{DISCUSSION}

This study was conducted to determine the cervical spine posture between subjects with and without TB therapy. Khoja et $\mathrm{al}^{7}$ reported an improvement in the sagittal skeletal relationships with the TB owing to an increase in the mandibular length. Aglarci ${ }^{23}$ investigated the effects of the TB on the sagittal skeletal dimensions and the cervical posture. The results showed a significant difference between the PF1 and PF2 SNB, ANB, and OPT/CVT angles, indicating an improvement in sagittal relationships and an increase in cervical curvature. Ohnmeiß et $\mathrm{al}^{24}$ also found a significant difference between the PF1 and PF2 ANB values. Similarly, a significant difference in the SNB and ANB angles in PF1 and PF2 indicated an improvement in the sagittal relationships in this study. Furthermore, a comparison of the changes in angular measurements between the groups also showed a significant difference. This establishes 
Table III. Comparison of the groups, median (interquartile range)

\begin{tabular}{|c|c|c|c|c|c|c|}
\hline \multirow[b]{2}{*}{ Angle } & \multicolumn{2}{|c|}{ Twin block $(n=30)$} & \multirow[b]{2}{*}{$\mathrm{P}$} & \multicolumn{2}{|c|}{ Control $(n=30)$} & \multirow[b]{2}{*}{$\mathrm{P}$} \\
\hline & $T 1$ & $T 2$ & & $T 1$ & $T 2$ & \\
\hline \multicolumn{7}{|c|}{ Sagittal parameters } \\
\hline $\mathrm{SNA}^{\circ}$ & $81.0(79.8-84.0)$ & $82.0(79.8-84.0)$ & 0.196 & $83.0(80.0-86.0)$ & $83.0(80.0-85.2)$ & 0.936 \\
\hline $\mathrm{SNB}^{\circ}$ & $75.0(73.0-77.0)$ & $75.0(73.0-77.0)$ & $<0.001^{\dagger}$ & $77.0(75.0-77.0)$ & $77.0(74.0-77.0)$ & 0.379 \\
\hline $\mathrm{ANB}^{\circ}$ & $6.5(5.0-8.0)$ & $5.0(3.0-6.0)$ & $<0.001^{\dagger}$ & $6.0(5.0-7.0)$ & $5.5(5.0-7.0)$ & 0.641 \\
\hline \multicolumn{7}{|c|}{ Vertical parameter } \\
\hline Sn-GoGn ${ }^{\circ}$ & $32.5(28-36)$ & $31.0(28-35)$ & 0.618 & $29.0(23-30)$ & $29.0(23-32)$ & 0.119 \\
\hline \multicolumn{7}{|c|}{ Upper cervical parameters } \\
\hline $\mathrm{SN}-\mathrm{OPT}^{\circ}$ & $105.0(100.0-110.5)$ & $104.0(100.0-110.0)$ & 0.386 & $95.0(88.0-101.5)$ & $97.0(93.0-103.5)$ & $0.033^{*}$ \\
\hline $\mathrm{PP}^{\mathrm{OOPT}}{ }^{\circ}$ & $97.0(94.8-101.0)$ & $95.5(92.5-103.3)$ & 0.665 & $90.5(88.0-97.0)$ & $92.0(88.0-94.2)$ & 0.287 \\
\hline $\mathrm{MP}-\mathrm{OPT}^{\circ}$ & $73.0(67.0-80.0)$ & $73.5(69.0-79.0)$ & 0.222 & $71.0(67.2-78.0)$ & $70.0(68.0-78.0)$ & 0.138 \\
\hline \multicolumn{7}{|c|}{ Middle cervical parameters } \\
\hline $\mathrm{SN}-\mathrm{CVT}^{\circ}$ & $104.5(100.8-113.0)$ & $106.0(102.8-114.8)$ & 0.683 & $100.0(96.7-108.2)$ & $100.0(97.2-108.0)$ & 0.396 \\
\hline $\mathrm{PP}-\mathrm{CVT}^{\circ}$ & $99.0(94.8-107.0)$ & $99.5(95.8-104.0)$ & 0.544 & $92.0(91.0-94.2)$ & $93.0(90.0-95.5)$ & 0.275 \\
\hline $\mathrm{MP}-\mathrm{CVT}^{\circ}$ & $75.0(72.0-83.0)$ & $78.0(70.0-80.0)$ & 0.793 & $73.0(66.7-77.2)$ & $72.5(69.5-81.2)$ & $0.013^{*}$ \\
\hline $\mathrm{OPT}^{-\mathrm{CVT}}{ }^{\circ}$ & $5.0(3.8-7.0)$ & $5.0(4.0-6.9)$ & 0.558 & $4.0(2.0-4.2)$ & $3.0(3.0-4.0)$ & 0.676 \\
\hline
\end{tabular}

${ }^{*} P \leq 0.05 ;{ }^{\dagger} P<0.001$; Wilcoxon signed-rank test.

Table IV. Cephalometric changes, median (interquartile range)

\begin{tabular}{|c|c|c|c|}
\hline Parameter & Twin block $(n=30)$ & Control $(n=30)$ & $P$ \\
\hline \multicolumn{4}{|c|}{ Sagittal parameters } \\
\hline SNA ${ }^{\circ}$ & $0.0(-1.3$ to 0.25$)$ & 0.0 (0.0 to 0.2$)$ & 0.236 \\
\hline $\mathrm{SNB}^{\circ}$ & $-2.0(-3.0$ to 1.0$)$ & $0.0(0.0$ to 0.0$)$ & $<0.001^{*}$ \\
\hline $\mathrm{ANB}^{\circ}$ & $1.5(1.0-3.0)$ & $0.0(-0.2$ to 0.0$)$ & $<0.001^{*}$ \\
\hline \multicolumn{4}{|c|}{ Vertical parameter } \\
\hline $\mathrm{SN}-\mathrm{GoGn}{ }^{\circ}$ & $0.0(-3.0$ to 2.0$)$ & $0.0(0.0$ to 0.0$)$ & 0.853 \\
\hline \multicolumn{4}{|c|}{ Upper cervical parameters } \\
\hline $\mathrm{SN}-\mathrm{OPT}^{\circ}$ & $1.0(-3.5$ to 5.0$)$ & $0.0(-1.2$ to 11.2$)$ & $0.032^{*}$ \\
\hline $\mathrm{PP}^{\mathrm{OOPT}}{ }^{\circ}$ & $2.0(-3.3$ to 6.0$)$ & $0.0(-5.2$ to 2.2$)$ & 0.805 \\
\hline $\mathrm{MP}-\mathrm{OPT}^{\circ}$ & $-0.5(-7.3$ to 2.3$)$ & $0.0(-5.5$ to 0.2$)$ & 0.189 \\
\hline \multicolumn{4}{|c|}{ Middle cervical parameters } \\
\hline $\mathrm{SN}-\mathrm{CVT}^{\circ}$ & $0.0(-5.0$ to 3.3$)$ & $0.0(-4.0$ to 0.2$)$ & 0.417 \\
\hline $\mathrm{PP}^{\mathrm{C}} \mathrm{CVT}^{\circ}$ & $0.0(-4.0$ to 3.3$)$ & $0.0(-0.5$ to 2.0$)$ & 0.994 \\
\hline $\mathrm{MP}-\mathrm{CVT}^{\circ}$ & $0.0(-6.0$ to 5.0$)$ & $1.5(0.0-5.2)$ & 0.153 \\
\hline $\mathrm{OPT}^{\mathrm{CPVT}}{ }^{\circ}$ & $0.0(-3.3$ to 2.0$)$ & $0.0(-1.0$ to 1.0$)$ & 0.770 \\
\hline
\end{tabular}

${ }^{*} P<0.001$; Mann-Whitney $U$ test.

that the faltering growth of the mandible had significantly improved relative to the maxilla and cranial base and emphasizes the consistent treatment success with the TB appliance. However, the success has been seen as a combination of inconsistent skeletal and dentoalveolar effects. This indicates the need for an alternate quantification of the improvement in skeletal relationships. ${ }^{25,26}$

The physiologic change in the cervical posture varies in different individuals. Müller ${ }^{27,28}$ claimed that the mandible acts in close harmony with a chain of muscles to control the position of the head in space and stated that craniofacial growth is evaluated more objectively
Table V. Probability of change in cervical posture after TB appliance therapy

\begin{tabular}{llccc}
$\begin{array}{l}\text { Cervical } \\
\text { parameter }\end{array}$ & Group & $\begin{array}{c}\text { Beyond } \\
\text { norm }\end{array}$ & $\begin{array}{c}\text { Within } \\
\text { norm }\end{array}$ & $\begin{array}{c}\text { Relative } \\
\text { risk }\end{array}$ \\
\hline PP-OPT $^{\circ}$ & TB & 16 & 14 & 3.20 \\
\hline SN-OPT $^{\circ}$ & Control & 05 & 25 & \\
& CB & 25 & 05 & 2.08 \\
MP-OPT $^{\circ}$ & TB & 28 & 18 & \\
& Control & 28 & 02 & 1.06 \\
SN-CVT $^{\circ}$ & TB & 20 & 10 & 1.81 \\
& Control & 11 & 19 & \\
PP-CVT $^{\circ}$ & TB & 14 & 16 & 3.50 \\
\hline MP-CVT $^{\circ}$ & Control & 04 & 26 & \\
& TB & 25 & 05 & 1.03 \\
OPT-CVT $^{\circ}$ & Control & 13 & 17 & \\
\hline & CB & 10 & 20 & 1.43 \\
& & 07 & 23 &
\end{tabular}

from the occipital structures at the junction between skull and trunk. The cervical posture is dependent on interactions within the musculoskeletal system and physiologic growth processes and there is a close anatomic relationship between the cervical spine and the mandible. ${ }^{29}$ In addition, the cervical spine has shown an association with the size of the mandible, craniofacial morphology,and mandibular divergence. ${ }^{30-33}$

Björk ${ }^{34-36}$ and Bjork and Skieller ${ }^{37,38}$ were the first to describe the rotation of the maxilla and the mandible during human growth and development. They described it in terms of either a forward or backward rotation. The influence of muscle attachments to the cervical vertebrae (C2) in the developing vertical growth pattern have been 
explained by the quadrant theorem of Guzay. ${ }^{39}$ It states that when the mandible moves downward, it generates a pulling force, loosening the muscles around C2. Likewise, when moving up, it generates pressure which tightens the muscles around C2. This means that an occlusion with a decreased vertical dimension will aggravate muscle tension around $\mathrm{C} 2$ when the mouth is closed. ${ }^{39}$

This interesting relationship between $\mathrm{C} 2$ and the mandible can be explained by the significant differences found between the SN-OPT and MP-CVT angles in subjects from the Bolton-Brush Growth Study. There was a significant increase noted in the SN-OPT angle between the T1 and T2 values of the unexposed group which indicates a change in the upper cervical posture making it more forwardly inclined with a retrognathic mandible. Compared with the exposed group, the decrease in the SN-OPT angle shows that there is an uprighting and development of a natural curvature of the spine with an improvement in the mandibular length.

The mean values of the mandibular plane angle in the unexposed group indicate that the selected subjects had skeletal Class 11 malocclusion due to mandibular retrognathism and a reduced vertical dimension. With the compelling evidence above, ${ }^{35-39}$ it can be clearly determined that these subjects would definitely have a greater physiologic change in their cervical posture, which is represented by the significant difference found between the MP-CVT angles taken at $T_{1}$ and $T_{2}$. The mean values of the mandibular plane angle in the exposed group indicate that a majority of the subjects had a normal vertical growth pattern, therefore no significant differences were noted in the PF1 and PF2 cervical parameters. Whereas Agalrci ${ }^{23}$ found a significant difference between the OPT-CVT angles, indicating a change in the middle cervical posture, Ohnmei $\beta$ et al ${ }^{24}$ did not find a significant difference between the cervical parameters. We found a significant difference in the mean change of the SN-OPT angle, which can be interpreted as an uprighting of the upper cervical posture. There was no significant change noted in the middle cervical posture in the exposed group (from $T_{1}$ to $T_{2}$ ), and the mean change between the groups also was nonsignificant.

The probability of altering the cervical posture with the use of the TB appliance was assessed using the measurements of the cervical parameters. The probability of altering the upper cervical posture was predicted with the use of the SN-OPT angle to be 2 times greater than without TB therapy. Although the results show many of the other parameters to be suggestive of an altered cervical posture, the results should be interpreted with caution because the other statistical evidence contradicts these findings.
The comparison group exhibited a normal physiologic forward inclination of the cervical posture which was significantly different from the intervention group who revealed a change to a more upright posture in the duration of appliance therapy. Although a comparison group was used in this study, it is based on a historical sample of the white population and makes a poor standard of comparison. A single-center study based on a 2-dimensional imaging technique, manual tracing of cephalometric landmarks, and measurements are all limitations of this study. These deficiencies can be overcome by obtaining a comparison group of individuals from the local population and using a 3-dimensional imaging technique.

\section{CONCLUSIONS}

This study was conducted to determine the cervical spine posture between subjects with and without TB therapy. We rejected the null hypothesis based on the following results:

1. The TB improves the sagittal relationships between the maxilla and mandible.

2. The TB causes the craniocervical posture to be more upright.

3. Subjects with Class 11 malocclusion due to mandibular retrognathism with a reduced vertical dimension have a greater forward inclination of the craniocervical posture.

4. The SN-OPT angle can predict a skeletal change in the maxillomandibular relationships.

\section{ACKNOWLEDGMENTS}

The authors express their gratitude to the AAO Foundation Craniofacial Growth Legacy Collection for providing full-size radiographic images from the Bolton-Brush Growth Study.

\section{REFERENCES}

1. Aslam A, Naeem A, Jan H, Bukhari GA, Abbas Q, Amjad M. Prevalence of Class 11 malocclusions in Pakistani sample-a study. Pak Oral Dent J 2010;30:96-100.

2. Bishara SE, Ziaja RR. Functional appliances: a review. Am J Orthod Dentofacial Orthop 1989;95:250-8.

3. Proffit WR, Fields HW, Sarver DM. Contemporary orthodontics. 5th ed. St Louis. Mo: Mosby Elsevier; 2007.

4. Clark WJ. The twin block traction technique. Eur J Orthod 1982;4: 129-38.

5. Gill D, Sharma A, Naini F, Jones S. The twin block appliance for the correction of Class 11 malocclusion. Dent Update 2005;32:158-68.

6. Ali B, Shaikh A, Fida M. Effect of Clark's twin-block appliance (CTB) and nonextraction fixed mechano-therapy on the pharyngeal dimensions of growing children. Dent Press J Orthod 2015; 20:82-8. 
7. Khoja A, Fida M, Shaikh A. Cephalometric evaluation of the effects of the twin block appliance in subjects with Class 11 Division 1 malocclusion amongst different cervical vertebral maturation stages. Dent Press J Orthod 2016;21:73-84.

8. Saikoski LZ, Cancado RH, Valarelli FP, de Freitas SKM. Dentoskeletal effects of Class 11 malocclusion treatment with the twin block appliance in a Brazilian sample: a prospective study. Dent Press J Orthod 2014;19:36-45.

9. Yaqoob O, Dibiase AT, Fleming PS, Cobourne MT. Use of the Clark's twin block functional appliance with and without an upper labial bow: a randomized controlled trial. Angle Orthod 2012;82:363-9.

10. Baccetti T, Franchi L, Toth LR, McNamara JA Jr. Treatment timing for twin-block therapy. Am J Orthod Dentofacial Orthop 2000; 118:159-70.

11. Pancherz H. A cephalometric analysis of skeletal and dental changes contributing to Class 11 correction in activator treatment. Am J Orthod 1984;82:104-13.

12. Proffit WR, Raymond PW, David MS. Contemporary treatment of dentofacial deformity. St Louis, Mo: Mosby; 2003.

13. Schwarz AM. Kopfhaltung und Kiefer. Z Stomatol 1926;24: 669-744.

14. Graber LW, Vanarsdall RL, Vig KW, Huang GJ. Orthodontics: current principles and techniques. Elsevier Health Sciences; 2016.

15. Gresham H, Smithells PA. Cervical and mandibular posture. Dental Rec 1954;74:261-4.

16. Morris DO, Illing HM, Lee RT. A prospective evaluation of bass, bionator and twin block appliances: part 11-the soft tissues. Eur J Orthod 1998;20:663-84.

17. Sidlauskiene M, Smailiene D, Lopatiene K, Cekanauskas E, Pribuisiene R, Sidlauskas M. Relationships between malocclusion, body posture, and nasopharyngeal pathology in pre-orthodontic children. Med Sci Monit 2015;21:1765-73.

18. Verma G, Tandon P, Nagar A, Singh GP, Singh A. Cephalometric evaluation of hyoid bone position and pharyngeal spaces following treatment with twin block appliance. J Orthodont Sci 2012;1:77-82.

19. Smailiene D, Intiene A, Dobradziejute 1, Kuslekia G. Effect of treatment with twin-block appliances on body posture in Class 11 malocclusion subjects: a prospective clinical study. Med Sci Monit 2017;23:343-52.

20. Broadbent BH Sr, Broadbent BH Jr, Golden WH. Bolton standards of dentofacial developmental growth. St. Louis, Mo: Mosby Elsevier; 1975.

21. Tecco S, Farronato G, Salini V, Meo SD, Filippi MR, Festa F, et al. Evaluation of cervical spine posture after functional therapy with FR-2: a longitudinal study. Cranio 2005;23:53-66.

22. Baccetti T, Franchi L, McNamara JA. The cervical vertebral maturation (CVM) method for the assessment of optimal treatment timing in dentofacial orthopedics. Semin Orthod 2005; 11:119-29.
23. Aglarci C. Evaluation of cervical spine posture after functional therapy with twin-block appliances. J Orthod Res 2016;4:6-12.

24. Ohnmeiß M, Kinzinger G, Wesselbaum J, Korbmacher-Steiner HM. Therapeutic effects of functional orthodontic appliances on cervical spine posture: a retrospective cephalometric study. Head Face Med 2014;10:7.

25. Perinetti G, Primožič J, Franchi L, Contardo L. Treatment effects of removable functional appliances in pre-pubertal and pubertal Class 11 patients: a systematic review and meta-analysis of controlled studies. PLoS One 2015;10:e0141198.

26. Santamaria-Villegas A, Manrique-Hernandez R, AlvarezVarela E, Restrepo-Serna C. Effect of removable functional appliances on mandibular length in patients with Class 11 with retrognathism: systemic review and meta-analysis. BMC Oral Health 2017;17:52.

27. Müller G. Erkennen und darstellen des wachstums an der synchondrosis spheno-occipitalis nach fernröntgenaufnahmen. Fortschr Kieferorthop 1959;20:80-3.

28. Müller G. Über die wachstumsbedingten lageveränderungen von sella turcica, nasion und porion in der norma lateralis nach fernröntgenaufnahmen. Fortschr Kieferorthop 1959;20:204-13.

29. Schafer RC. Clinical biomechanics: musculoskeletal actions and reactions. 2nd ed. Baltimore, Md: Williams and Wilkins; 1987.

30. Springate SD. A re-investigation of the relationship between head posture and craniofacial growth. Eur J Orthod 2012;34:397-409.

31. Festa F, Tecco S, Dolci M, Ciufolo F, di Meo S, Filippi MR, et al. Relationship between cervical lordosis and facial morphology in Caucasian women with a skeletal Class 11 malocclusion: a crosssectional study. Cranio 2003;21:121-9.

32. Liu HH, Lin H, Sun Y, Tao L. A correlate study on the first cervical vertebra and mandibular growth: a comparison of Shanghai females between 12 and 15 years old. Shanghai Kou Qiang Yi Xue 1998;7:163-6.

33. Huggare J. The first cervical vertebra as indicator of mandibular growth. Eur J Orthod 1989;11:10-6.

34. Björk A. Variations in the growth pattern of the human mandible: longitudinal radiographic study by the implant method. J Dent Res 1963;42:400-11.

35. Björk A. Prediction of mandibular growth rotation. Am J Orthod 1969;55:39-53.

36. Björk A. The role of genetic and local environmental factors in normal and abnormal morphogenesis. Acta Morphol Neerl Scand 1972;10:49-58.

37. Björk A, Skieller V. Facial development and tooth eruption: an implant study at the age of puberty. Am J Orthod 1972;62:339-83.

38. Björk A, Skeiller V. Normal and abnormal growth of the mandible: a synthesis of longitudinal cephalometric implant studies over a period of 25 years. Eur J Orthod 1983;5:1-46.

39. Guzay CM. Introduction to the quadrant theorem. Basal Facts 1976;1:153-60. 